\title{
Biomass Extraction and Economic Growth in Developing China: 1970-2010
}

\author{
Fengmei Ma ${ }^{1, a}$, Guangsheng Zhang ${ }^{1, b^{*}}$, Heming Wang ${ }^{2, c}$, Qiang Yue ${ }^{2, d}$, Jian \\ Wang $^{2, e}$ and Tao Du ${ }^{2, f}$ \\ ${ }^{1}$ Shenyang Agricultural University, China \\ ${ }^{2}$ Northeastern University, China \\ amafm08@hotmail.com, bgshzhang@163.com, cwanghm@smm.neu.edu.cn, \\ dyueq@smm.neu.edu.cn, ${ }^{\mathrm{e}}$ wangjian_2016@hotmail.com, ${ }^{\mathrm{f}}$ dut@ smm.neu.edu.cn.
}

${ }^{*}$ The corresponding author

Keywords: Biomass extraction; Economic growth; Decomposition analysis; Decoupling

\begin{abstract}
Natural resources, including biomass resources, provide the basis for our life on Earth. The using of them also brings pressure on the environment. It is important for China to analyze the biomass extraction during its economic growth. In this study, we followed the guideline from Eurostat office to compile the account of China's biomass extraction during 1970-2010. Furthermore, using decomposition, we examine factors that have influenced changes in this indicator in China. Results show that China had a rapid increase in DE of biomass, which more than doubled, from 1354 million tons (Mt) to $3229 \mathrm{Mt}$. The factor of Affluence $(A)$ made the largest contribution, and the improvement of Resource use intensity $(T)$ played an important role in decreasing it. It is suggested to make further efforts to improve the Resource use intensity $(T)$ to decouple China's biomass extraction from economic growth abosolutely.
\end{abstract}

\section{Introduction}

Natural resources, including biomass resources, provide the basis for our life on Earth. However, while these resouces provide us convenience, the using of them also brings pressure on the environment. Since Chinese economic reform, both GDP and resource consumption have increased dramatically over the past decades $[1,2,3,4]$. Therefore, the case of China provides a timely example of the relationship between economic growth and resource consumption during its economic transition process.

Most of previous studies have focused on several highly intergrated material flow indicators, such as Domestic Material Consumption (DMC) and Dirtect Material Input (DMI) to stduy the relationship between economic growth and resource consumption. Nomally, these indicators include four material groups: biomass, construction minerals, fossil fuels, metal ores and industrial minerals. However, few study focus on biomass resource itself. As biomass resource is a very important kind of resource, which provides humanity the base to live, this study chooses to analyze the biomass resouce use of China during 1970-2010. As the international trade data of biomass during the studied period are not sufficent, this study chooses Domestic Extraction (DE) of biomass as a material flow indicator. Because the imported and exported amount of biomass is quite small, compared to the extraction amount, Domestic Extraction (DE) of biomass can be regarded to relect the consumption condition of China. Apart from presenting DE of biomass of China, this article would also examine the driving factors that have changed recent DE of biomass in China during 1970-2010, using a decomposition method. At last, suggestions based on the decomposition analysis are provided.

\section{Methods and Data}

Decomposition Method. Since the 1970s, decomposition analysis has been firstly used in the field of energy consumption [5]. In recent years, this technique has been used as an important tool for examining the driving factors that have changed material flow indicators [6]. 
This study undertook decomposition analysis of DE of biomass in China using the following equation.

$$
D E=P \times \frac{G D P}{P} \times \frac{D E}{G D P}=P \times A \times T
$$

In this equation, $D E$ represents the Domestic Extraction; $P$ represents population; GDP is given in U.S dollars of the price of 2000. Eq. 1 was developed from the well-known IPAT identity [7]. In Eq. 1, there are three factors influencing DE:

The first factor $(P)$ represents Population. This factor is especially important for developing countries which have high population growth, such as China and India. The newly added population normally means added material consumption, and thus this factor is regarded as a main influential factor of DE.

The second factor $(A)$ is Affluence, which is expressed as GDP per capita. It is normal that with the increase of income level of one country, more products or materials would be consumed. Therefore, the factor of Affluence is normally regarded as a key driving force for increasing DMC.

The third factor $(T)$ in Eq. 1 is DE per unit of GDP. This factor represents Resource use intensity for the purposes of this study. In Eq. 1, factor $T$ is the residual, which means everything that affects DE except Population and Affluence. Some important factors associated with $T$, such as economic structure and consumption pattern, indirectly influence DE.

If changes in these factors described above can explain the variations of DE, then this change can be expressed via the following equation. An additive form for this explanation is used in this study.

$$
\Delta D E=P_{\text {effect }}+A_{\text {effect }}+T_{\text {effect }}
$$

Here, $P_{\text {effect }}, A_{\text {effect }}$, and $T_{\text {effect }}$ are respective effects of factors $P, A$, and $T$ on changes in DE. The calculation equations of these factors are in the following equations.

$$
\begin{aligned}
& P_{\text {effect }}=a^{0} t^{0} \Delta p+\frac{1}{2} \Delta p\left(a^{0} \Delta t+t^{0} \Delta a\right)+\frac{1}{3} \Delta a \Delta p \Delta t \\
& A_{\text {effect }}=p^{0} t^{0} \Delta a+\frac{1}{2} \Delta a\left(p^{0} \Delta t+t^{0} \Delta p\right)+\frac{1}{3} \Delta a \Delta p \Delta t \\
& T_{\text {effect }}=a^{0} P^{0} \Delta t+\frac{1}{2} \Delta t\left(p^{0} \Delta a+a^{0} \Delta p\right)+\frac{1}{3} \Delta a \Delta p \Delta t
\end{aligned}
$$

Here, $p^{0}, a^{0}$, and $t^{0}$ represent the value of $P, A$, and $T$ in the base year, and $\Delta p, \Delta a$, and $\Delta t$ represent the changeing value of $P, A$, and $T$ in the studied period, respectively.

Data Collection. The DE data of biomass for China is from FAO online database [8].The DE accounts were compiled following the guideline of Eurostat 2009 [9]. Three material groups are include in DE of biomass: Primary crops, Crop residues and grazed biomass, and wood.

Data of GDP and population is from China Statistical Yearbooks [10].

\section{Results and Analysis}

The DE of Biomass. Fig. 1 shows China's DE of biomass for 1970-2010. A continuous increase is apparent. During this period, China's DE of biomass more than doubled, rising from 1354 million tons $(\mathrm{Mt})$ to $3229 \mathrm{Mt}$. The average annual growth rate is $2.2 \%$, much lower than the rate of GDP growth, which is as high as $9.1 \%$.

If we divide the biomass extraction into three main groups, from Fig. 2 we can find that the strongest growth is observed for primary crops, which more than tripled, from $455.2 \mathrm{Mt}$ to $1580.6 \mathrm{Mt}$. The average annual growth rate is as high as $3.16 \%$. The average annual growth rate of crop residues and grazed biomass is $2.02 \%$, and their total amount more than doubled, from $668.4 \mathrm{Mt}$ to $1484.7 \mathrm{Mt}$. The wood extraction has a quite different trend. The DE of wood decreased by about $30 \%$, from 230.9 Mt to $163.8 \mathrm{Mt}$, and its average annual decreasing rate is $0.85 \%$.

If we have a look at the respective shares of these three biomass types, we can find before 2000, the share of crop residues and grazed biomass is the largest one, which is near to $50 \%$. However, after 
2000, with the rapid growth of primary crops, the share of crop residues and grazed biomass is lower than primary crops. In addition, the share of wood has been the lowest one, decreasing from $17 \%$ to $5 \%$.

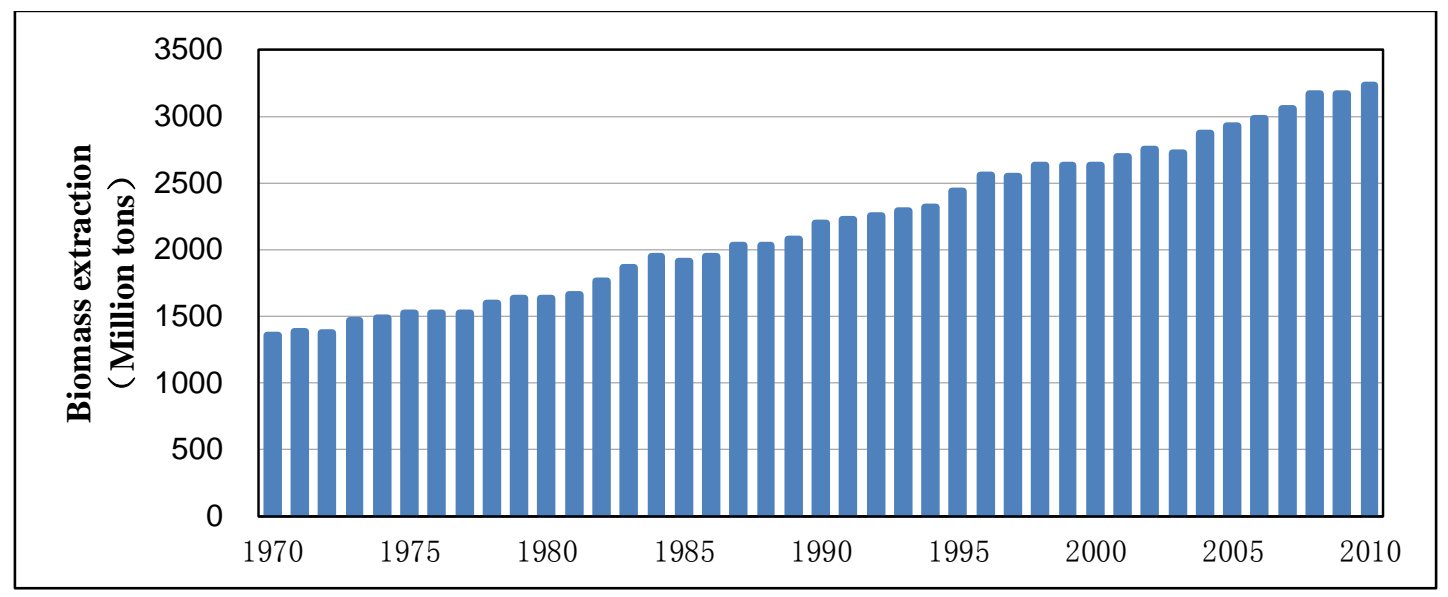

Figure 1. Changes in China's biomass extraction during 1970-2010

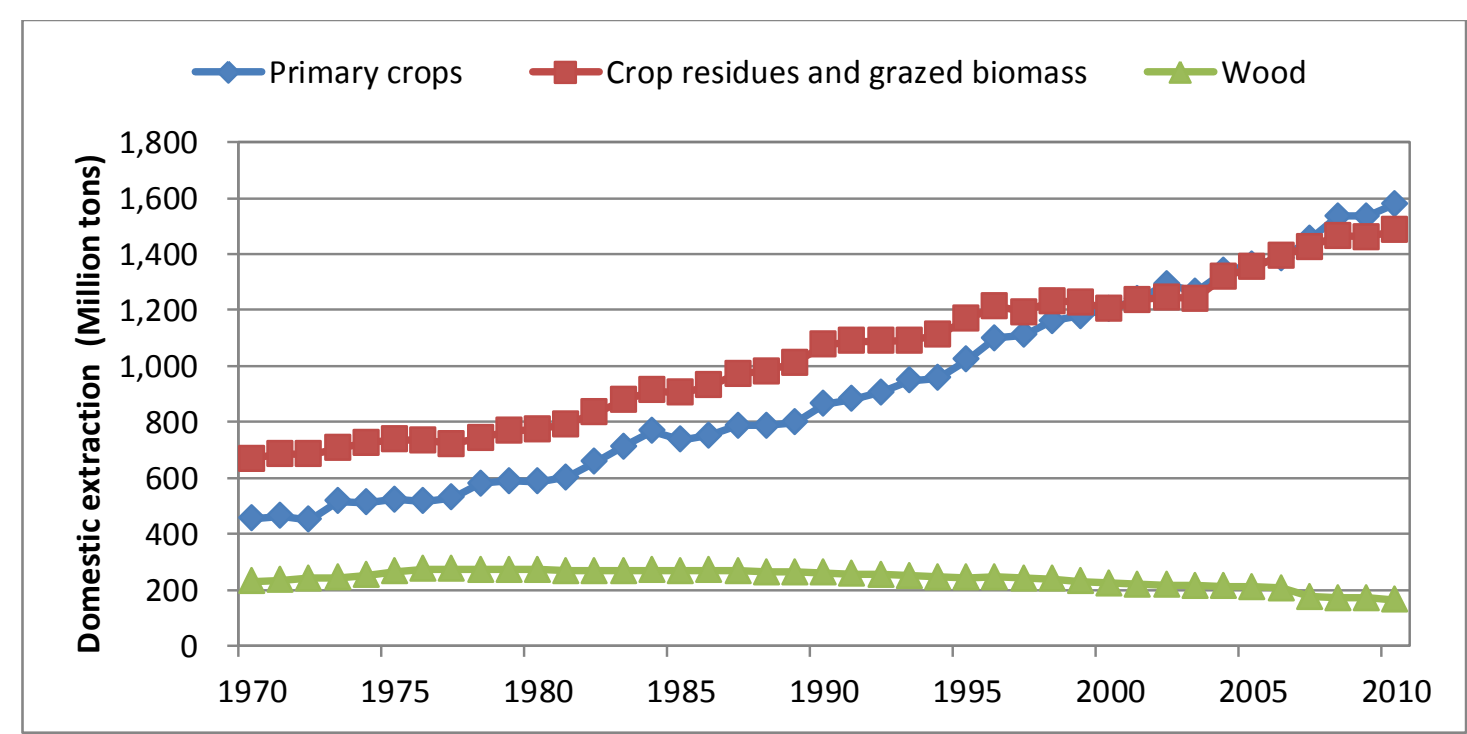

Figure 2. Changes of three material groups of China's biomass extraction during 1970-2010

As the primary crops have the largest increasing rate, it is interesting to have a deep analysis on its subdivision. In Fig. 3, we can have a clear view of the trend of its ten categories. The extraction of cereals accounted for the largest during the studied period. It is also clear to see that the extraction of vegetables and fruits has the largest increasing rates. The increasing factors of them are 12.7 and 19.8, respectively, compared with the increasing factor of cereals as 2.5 . These transition could reflect that the change of consumption structure of biomass for Chinese people during the economic growth. 


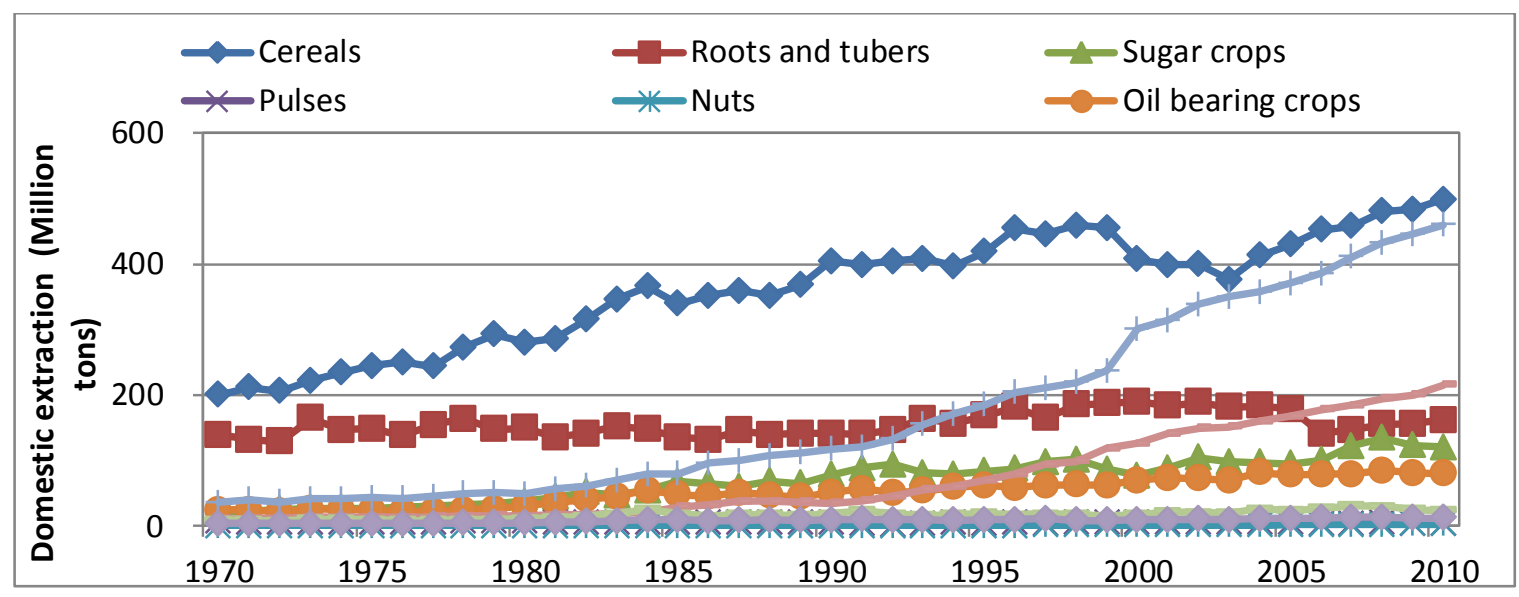

Figure 3. Changes of different categories of primary crops during 1970-2010

Decomposition Analysis of China's DE of Biomass. Contributions by the three factors to the changes in China's DE of biomass are shown in Fig. 4A. During 1970-2010, the Affluence $(A)$ made the largest contribution to increasing China's DE of biomass by $6971 \mathrm{Mt}$, but the opposite effect from improvement of Resource use intensity $(T)$ largely decreased DE of biomass by $6046 \mathrm{Mt}$. In addition, the Population $(P)$ contributed $950 \mathrm{Mt}$ to increasing China's DE of biomass. Consequently, China's DE of biomass increased by $1875 \mathrm{Mt}$ during 1970-2010. It is suggested to improve the Resource use intensity $(T)$ further to have an absolute decoupling between biomass extraction and economic growth.

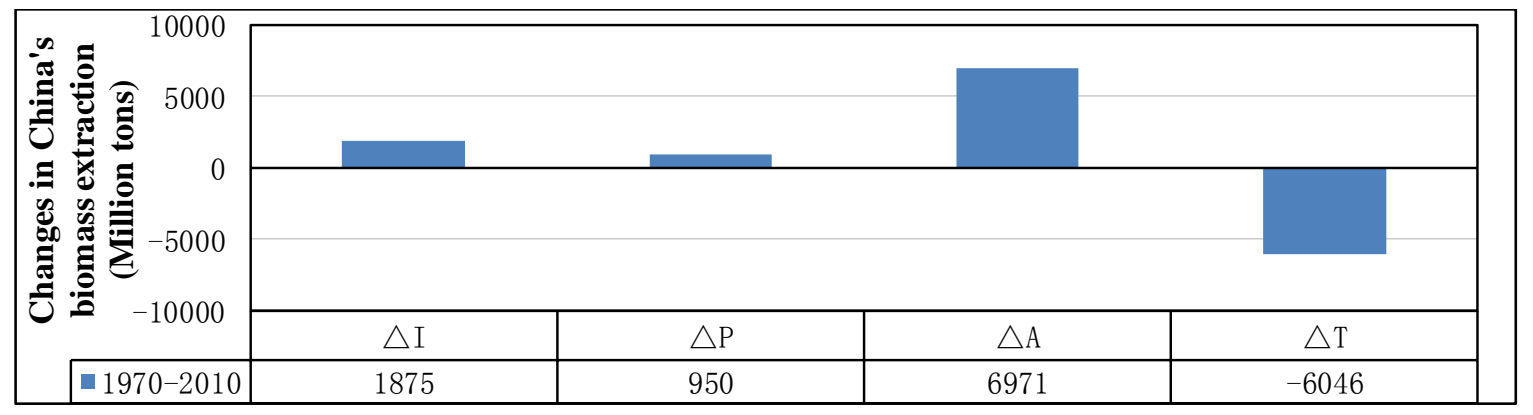

A.

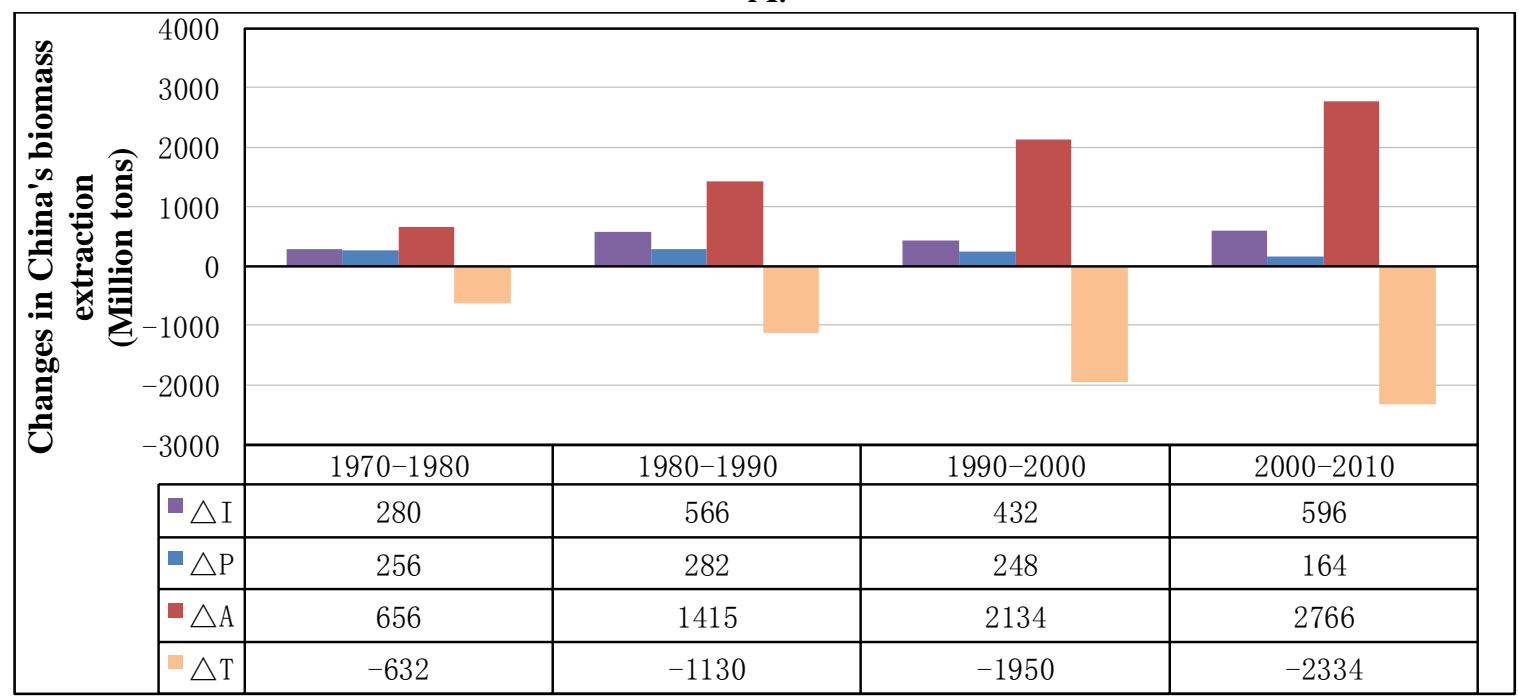

B.

Figure 4. Changes in China's biomass extraction and contributions of respective factors during 1970-2010 
Fig. 4B shows China's DE of biomass changes by these factors every 10 years. In the periods of 1970-1980, 1980-1990, 1990-2000, and 2000-2010, China's DE of biomass increased mainly dirven by the Affluence $(A)$ factor, and the improvement of Resource use intensity $(T)$ made the greatest contribution to offset it. In the period of 2000-2010, we can obeserve the largest increment of China's DE of biomass, which is $596 \mathrm{Mt}$.

\section{Conclusion}

This article has examined the China's biomass extraction, and analyzed the driving factors that have changed it during 1970-2010, using a decomposition method. Conclusions drawn from the analyses described above are the following. China had a rapid increase in DE of biomass, which more than doubled, from 1354 million tons (Mt) to $3229 \mathrm{Mt}$. The factor of Affluence $(A)$ made the largest contribution, but the improvement of Resource use intensity $(T)$ played an important role in decreasing it. It is suggested to improve the Resource use intensity $(T)$ further to have an absolute decoupling between biomass extraction and economic growth.

\section{Acknowledgement}

This research was financially supported by the National Natural Science Foundation of China (71403175, 71273179, 41401636, 71373003, 51474067), Fundamental Research Funds for the Central Universities (N140204007), MOE Project of Humanities and Social Sciences (13YJCZH172, 13YJC790106), Foundation of Liaoning Distinguished Professor Planning(2013), and Key Programs on Social Development of Liaoning Province (2012201011).

\section{References}

[1] H. Schandl and J. West: Global Environmental Change, Vol. 20 (2010) No.4, p.636-647.

[2] H. Wang, X. Tian, H. Tanikawa, M. Chang, S. Hashimoto, Y. Moriguchi and Z. Lu: Environmental Science and Technology, Vol. 48 (2014) No.9, p.5025-5032.

[3] H. Wang, S. Hashimoto, Q. Yue, Y. Moriguchi and Z. Lu: Journal of Industrial Ecology, Vol. 17 (2013) No.4, p.618-629.

[4] H. Wang, S. Hashimoto, Y. Moriguchi, Q. Yue and Z. Lu: Journal of Industrial Ecology, Vol. 16 (2012) No.4, p.481-492.

[5] B.W. Ang and F.Q. Zhang: Energy, Vol. 25 (2000) No.12, p.1149-1176.

[6] Hashimoto, S., S. Matsui, Y. Matsuno, K. Nansai, S. Murakami and Y. Moriguchi: Journal of Industrial Ecology, Vol. 12 (2008) No.5-6, p.657-668.

[7] B. Commoner: The environmental cost of economic growth (Government Printing Office, Washington DC 1972).

[8] Fao. 2016. FAO Statistical Databases. <http://faostat.fao.org> . Accessed January 2016.

[9] Eurostat: Economy-wide material flow accounts: Compilation guidelines for reporting to the 2009 Eurostat questionnaire (European Statistical Office, Luxembourg 2009).

[10]National Bureau of Statistics of China: China Statistical Yearbook 2015 (China Statistics Press, Beijing 2015). 